\title{
The effects of rhBMP-2 on bone healing in ovariectomized rats treated with zoledronic acid and dexamethasone.
}

\author{
Berkem Atalay $^{\text {* }}$, Fatih Cabbar ${ }^{2}$, Nurhan Guler ${ }^{2}$, Kemal Sencift ${ }^{2}$ \\ ${ }^{1}$ Department of Oral Surgery, Istanbul University, Istanbul, Turkey \\ ${ }^{2}$ Department of Oral Surgery, Yeditepe University, Istanbul, Turkey
}

\begin{abstract}
Background/aim: The aim is to determine the histological findings of recombinant human bone morphogenetic protein-2 (rhBMP-2) on bone healing after zoledronic acid (ZOL) treatment in ovariectomized rats.

Materials and methods: The study was performed on 42 female Sprague-Dawley rats untreated for $4 \mathrm{w}$ after ovariectomy. Fourteen rats were injected with $7.5 \mu \mathrm{g} / \mathrm{kg} \mathrm{ZOL}$ once a week, and $1 \mathrm{mg} / \mathrm{kg}$ dexamethasone per day served as control. Two groups of 14 rats were injected with the same dosage as a control group for once a week for two weeks (group A) and three weeks (group B). The molar teeth in both jaws were extracted two weeks after the first injection for the control group and group $A$ and three weeks for group B. Collagen carriers with rhBMP-2 were implanted into the extraction sockets in groups $A$ and $B$. The histological findings of new bone formation, and necrotic bone were recorded.

Results: The new bone formation was observed in $71.4 \%$ of group $A$ and $28.6 \%$ of group $B(P=0.017)$. Necrotic bone was observed in $\mathbf{1 4 . 3 \%}$ of both the control group and group $A$ and $\mathbf{7 1 . 4 \%}$ of group B $(\mathrm{P}=\mathbf{0 . 0 3 2})$.

Conclusion: An increased rhBMP-2 dosage on bone healing after ZOL treatment in ovariectomized rats could lead to new bone formation.
\end{abstract}

Keywords: Zoledronic acid, Osteonecrosis, Recombinant human bone morphogenetic protein-2. Accepted on September 20, 2018

\section{Introduction}

The effect of bisphosphonates on bone metabolism is led by the inhibition of osteoclastic activity, which is directly responsible for bone resorption. Moreover, it also has antitumor effects, including tumor cell uptake in the extracellular matrix, the inhibition of tumoral invasion and apoptosis of tumor cells [1,2]. In oncology patients receiving high-dose intravenous bisphosphonate, bisphosphonate-related osteonecrosis of the jaw (BRONJ) dependent on the dose and duration of therapy, with an estimated incidence of $1 \%-12 \%$ at 36 months of exposure [3].

Today, bisphosphonates have a broad range of use across many diseases due to their effects on bone metabolism and increase the life quality of patients. However, they are also reported to have side effects, including gastrointestinal intolerance, oesophagal ulcer, renal toxicity, acute renal failure, electrolyte imbalances, atrial fibrillation, fever, myalgia, influenza, and BRONJ [4-8].

The potency of ZOL is 100 and ten times higher than that of pamidronate and ibandronate, respectively [9]. It is claimed that ZOL inhibits the formation of osteoclasts and osteoclastic resorption activity, and therefore may deteriorate bone turnover. It prevents the resorption of hydroxyapatite, the migration of osteoclasts to the resorption site, and the dissemination of tumor cells to the bone matrix [10-12]. It is reported that the higher vascularization and turnover of jawbones than other bones of the body cause higher bisphosphonate concentrations. The relationship between remodelling suppression and damage accumulation in bone has repeatedly been shown in pre-clinical animal models at different doses and over different periods of time [13]. The amount of microdamage that accumulates at different skeletal sites varies and is greater in cancellous bone [14]. Micro damages occur in the acellular and avascular bone caused by bisphosphonates due to the generation of high bone turnover rate around periodontium caused by mastication and periodontal ligaments surrounding the teeth. The thin oral mucosa is traumatized or may be damaged during surgery and bacteria found in the oral flora may reach the necrotic bone [15].

BRONJ is defined as necrotic bone development persisting over eight weeks in the jawbones of patients receiving bisphosphonate but not undergoing neck-head radiotherapy [4]. The lesions associated with BRONJ are characterized as yellowish-white bone areas but may also appear as extraoral or 
intraoral fistulas and ulcerations around the lesion. Orofacial pain, toothache, trismus, and chronic sinusitis or cutaneous fistulas caused by oroantral fistulas are typical for these patients $[16,17]$.

The ovariectomized rat model was studied mostly for osteoporosis. Following ovariectomy, this model shows a biphasic loss of bone, with an initial rapid phase of bone loss followed by an intermediate period of relative stabilization of cancellous bone volume at an osteopenia level. The mechanism of bone loss currently accepted for the estrogen-deficient rat skeleton is an imbalance in bone turnover. The ovariectomized rat model mimics postmenopausal cancellous bone loss [18]. Therefore, studies are conducted on animal models that have undergone the same conditions as patients receiving bisphosphonate [19-22].

It was demonstrated that BMP's are found in trace amounts in the body. Osteoblasts and osteocytes synthesize them and are in the bone and dentin $[23,24]$. In the study conducted by Boyne, where segmental defects created in the mandibles of monkeys were treated using rhBMP-2/collagen, it is reported that regeneration was observed in critical-sized defects of all animals [25].

In the treatment of osteonecrosis found in the patients receiving bisphosphonate, the efficiency of mechanisms facilitating bone recovery and preventing the development of complications is not known. In this study considering the age and gender of patients with systemic disorders potentially requiring the use of bisphosphonates, the aim was to investigate experimentally the effect of rhBMP-2 on wound recovery in the tooth extraction region in ovariectomized rats that were administered ZOL after ovariectomy.

\section{Materials and Methods}

The Yeditepe University Institutional Animal Care and Use Ethical Committee approved all experimental procedures (Registration number: 19012009). Forty-two Sprague-Dawley rats (female, $12 \mathrm{w}$ old, and $225 \pm 21.34 \mathrm{~g}$ ) were used in this study. They were individually numbered using an ear punch, and three were housed per labelled cage in cages with filtered air at $21^{\circ} \mathrm{C}$ and $50 \pm 20 \%$ relative humidity. They were fed a standard diet of rat chow and watered ad libitum.

All rats were divided into three groups. Before each operation, the rats were anaesthetized with a single intraperitoneal injection of $50 \mathrm{mg} / \mathrm{kg}$ ketamine $\mathrm{HCl}$ (Ketalar, $50 \mathrm{mg} / \mathrm{ml}$, Eczacibası, Istanbul, Turkey) and $10 \mathrm{mg} / \mathrm{kg}$ xylazine (Rompun, $23.32 \mathrm{mg} / \mathrm{ml}$, Bayer, Istanbul, Turkey). The rats were untreated for the first four weeks following ovariectomy to allow the development of osteopenia. After four weeks, fourteen rats were injected with $7.5 \mu \mathrm{g} / \mathrm{kg} \mathrm{ZOL}$ a week and $1 \mathrm{mg} / \mathrm{kg}$ dexamethasone (DX) every day for two weeks; these served as a control group. Twenty-eight rats were divided into two groups, and the same control dosages were given for two weeks (group A) and three weeks (group B). Right maxillary and mandibular molar teeth extracted on $15^{\text {th }} \mathrm{d}$ after first injection in control group and group $\mathrm{A}$, and on $21^{\text {st }} \mathrm{d}$ in group
B. The teeth were removed using a dental explorer to loosen the cervical portion of each tooth by running the tip of the explorer around the tooth and then extracting the tooth by luxation. Before the wounds were sutured with 5-0 Vicryl (Ethicon US, LLC), collagen carrier with $2 \mu \mathrm{g}$ rhBMP-2 was implanted in the extraction sockets in groups A and B (Figure 1).

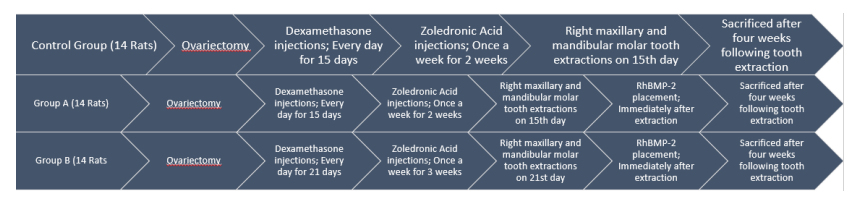

Figure 1. The timeline of the study.

RhBMP-2 (R\&D Systems, Inc., Minneapolis, MN, USA) obtained from Escherichia coli for placement into tooth extraction sockets was used according to the recommendations of the manufacturer. One $\mathrm{ml}$ phosphate buffer saline solution containing $0.1 \%$ bovine albumin was added to bottles containing lyophilized ten $\mu \mathrm{g}$ rhBMP-2 to obtain a concentration of $0.01 \mu \mathrm{g}$ rhBMP-2 per microliter. Using a specific pipette with a sterile tip, $200 \mu \mathrm{l}$ of the solution was added to a $5 \times 5 \times 5 \mathrm{~mm}$ collagen sponge prepared as a sterile transporter.

Two weeks after the first injection for the control group and group A, and three weeks for group B, collagen carrier with 2 $\mu \mathrm{g}$ rhBMP-2 was implanted in the extraction sockets in groups $\mathrm{A}$ and B. All the animals were sacrificed after four weeks following teeth extractions. The upper and lower jaws of the rats were resected, excess soft tissue was trimmed, and the remaining bones were fixed in 10\% formalin for at least $24 \mathrm{~h}$. They were then decalcified in an HCL/EDTA decalcifying solution for $72 \mathrm{~h}$ before being dissected, embedded in paraffin, cut into $5 \mu \mathrm{m}$ sections, and stained with hematoxylin and eosin (Table 1).

In all groups, the weights of the rats were measured during ovariectomy, tooth extraction, first injection, and sacrifice. One pathologist, blinded to the clinical data and groups, examined all histological findings. Histological findings on inflammation, new bone formation, and necrotic bone presence were recorded according to the appearance levels. The levels of the histological findings were classified as presence $(+)$, advanced $(++)$ and more advanced $(+++)$.

\section{Statistical analyses}

Statistical analyses were performed using NCSS (Number Cruncher Statistical System) 2007 PASS 2008 Statistical Software (NCSS Statistical Software, Kaysville, Utah, USA). One-way ANOVA test was used for the relationship between the variables, and Tukey's HSD test was employed for group comparisons. Analysis of variance was used for evaluation of weight changes within groups. The post-hoc Bonferroni test was used for the determination of the significant period. Qualitative data were compared using the chi-squared and Fisher's exact tests. A statistically significant difference was considered at $\mathrm{P}<0.05$. 


\section{Results}

A statistically significant difference was found in all procedure time intervals in the body weights of the rats in the three groups $(\mathrm{P}<0.01)$. The decrease in body weight in all groups between the first injection to the tooth extraction was statistically significant $(\mathrm{P}<0.001)$, while no significant difference was found between the first injection and the sacrifice period in the control group and group $\mathrm{A}(\mathrm{P}=0.589$; $\mathrm{P}>0.05)$. The increase in the body weight of the rats from the tooth extraction to the sacrifice time was found to be highly significant in all groups $(\mathrm{P}=0.001 ; \mathrm{P}<0.01)$.

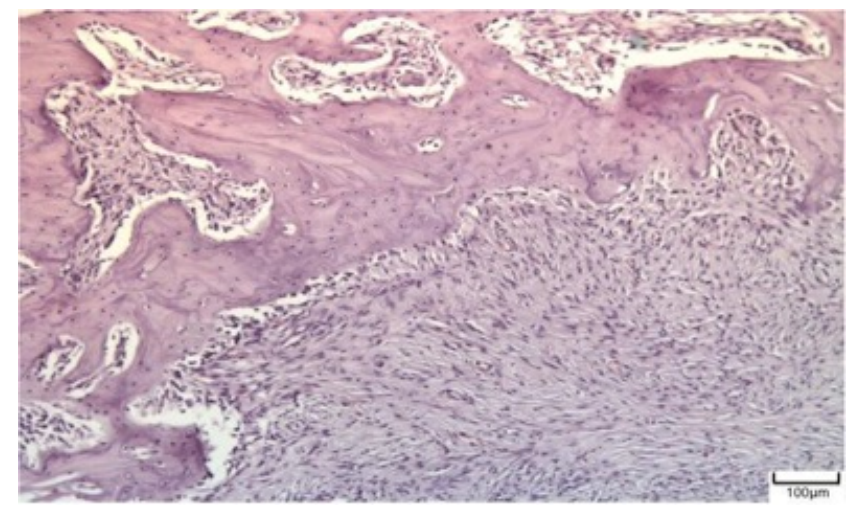

Figure 2. New bone formation of extraction socket in maxilla, Control (HE X100).

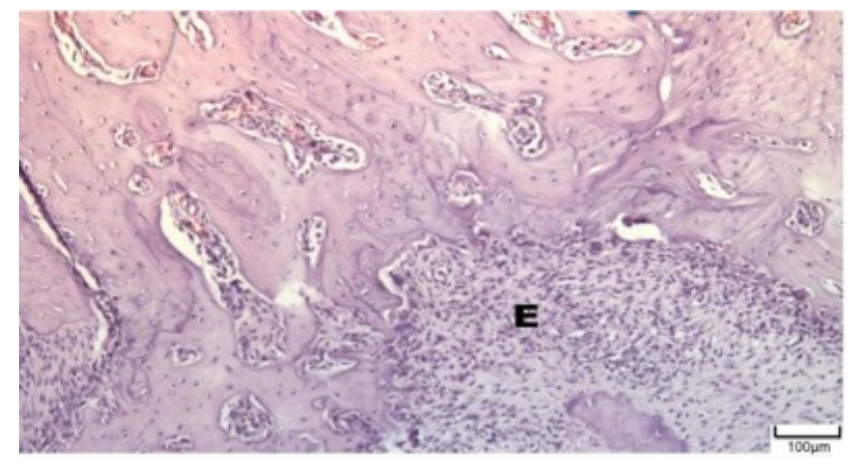

Figure 3. New bone formation of extraction socket (E) in mandible, control (HE X100).

A statistically significant difference was found among all groups regarding the increase in body weight within the period from the ovariectomy procedure to the sacrifice $(\mathrm{P}<0.05)$. While there was no significant difference in the level of increase observed during the post-ovariectomy to the sacrifice period in the control group and group $\mathrm{A}(\mathrm{P}=0.847 ; \mathrm{P}>0.05)$, the increase in the body weight of the rats in group $\mathrm{B}$ was found to be significantly lower than the body weight values of the rats in the control group $(\mathrm{P}=0.013 ; \mathrm{P}<0.05)$ and group $\mathrm{A}(\mathrm{P}=0.049$; $\mathrm{P}<0.05)$. The mean body weight between the ovariectomy and the sacrifice period in all groups was $63.64 \pm 28.97,59.12 \pm$ 19.07 , and $39.03 \pm 14.69$, respectively $(\mathrm{P}=0.011)$ (Tables 2 and $3)$.

The distribution of histologic findings in all specimens from each group is shown in Table 4. While severe inflammation was observed in all rats $(100 \%)$ in group B, inflammation with the same severity was observed in 10 rats $(71.4 \%)$ in the control group and $8(57.1 \%)$ in group $\mathrm{A}(\mathrm{P}=0.025)$. No statistically significant difference was observed in inflammation levels between all groups $(\mathrm{P}<0.05)$. The severity of inflammation in group $\mathrm{B}$ was significantly higher than in group A $\quad(\mathrm{P}=0.016 ; \quad \mathrm{P}<0.05)$. A statistically significant difference was observed in new bone formation levels of the rats in all groups in the tooth extraction region $(\mathrm{P}<0.01)$. The new bone formation level of group $\mathrm{A}$ was found to be significantly higher $(\mathrm{P}<0.05 ; \mathrm{P}<0.01)$ than in the control group and group $\mathrm{B}(\mathrm{P}=0.001$ and $\mathrm{P}=0.018$, respectively). While an advanced level of new bone formation was observed in 12 $(85.7 \%)$ rats in group $\mathrm{A}$ and $5(35.7 \%)$ in group $\mathrm{B}$, the new bone formation level of group $\mathrm{B}$ was found to be significantly higher than that of the control group $(\mathrm{P}=0.041 ; \mathrm{P}<0.05)$. While sequester was observed in $8(57.1 \%)$ rats in group $\mathrm{B}$, it was observed in $1(7.1 \%)$ in the control group and $2(14.3 \%)$ in group A $(\mathrm{P}=0.005)$. The sequester presence in group $\mathrm{B}$ $(\mathrm{P}<0.05)$ was found to be significantly higher than the control and group $\mathrm{A}(\mathrm{P}=0.013$ and $\mathrm{P}=0.046$, respectively).

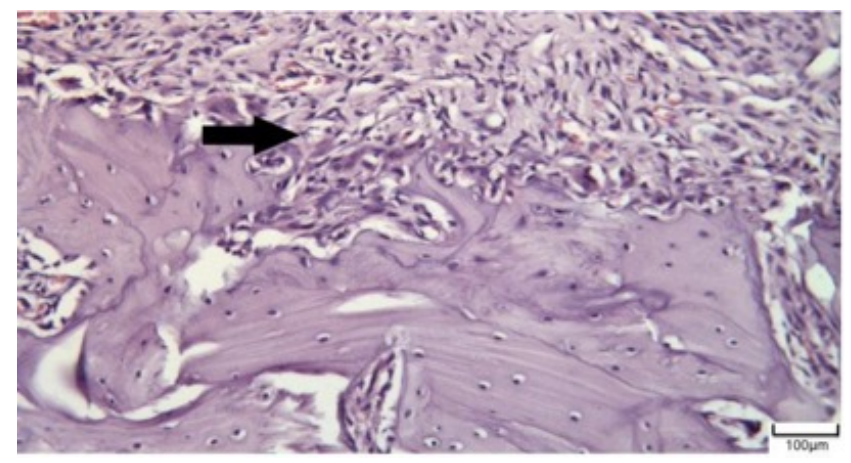

Figure 4. Osteoblastic activity in new bone formation of extraction socket in maxilla, Group A (HE X200).

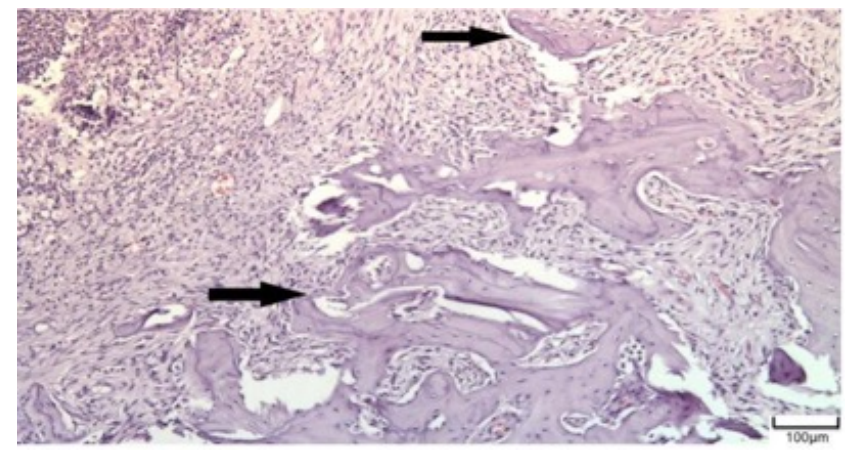

Figure 5. New bone formation of extraction socket (arrow) in mandible, group A (HE X100).

The distribution of severe inflammation in the maxilla and mandibles in all groups were as follows. All 7 (100\%) mandibles in the control group and group B demonstrated inflammation, while it was observed equally in both jaws in 4 rats $(57 \%)$ in group B. Advanced new bone formation in the maxilla and mandibles of the control group was observed in all specimens (Figures 2 and 3), while it was $7(100 \%)$ and 5 (71\%) in group A (Figures 4 and 5) and 3 (43\%) and 2 (29\%) 
in group B (Figures 6 and 7). The distribution of the presence of sequester in the maxilla and mandibles of all groups was 1 (14\%) mandible in the control group, $1(14 \%)$ maxilla and 1 (14\%) mandible in group A, and 3 (43\%) maxilla and $5(71 \%)$ mandibles in group B (Figure 8).

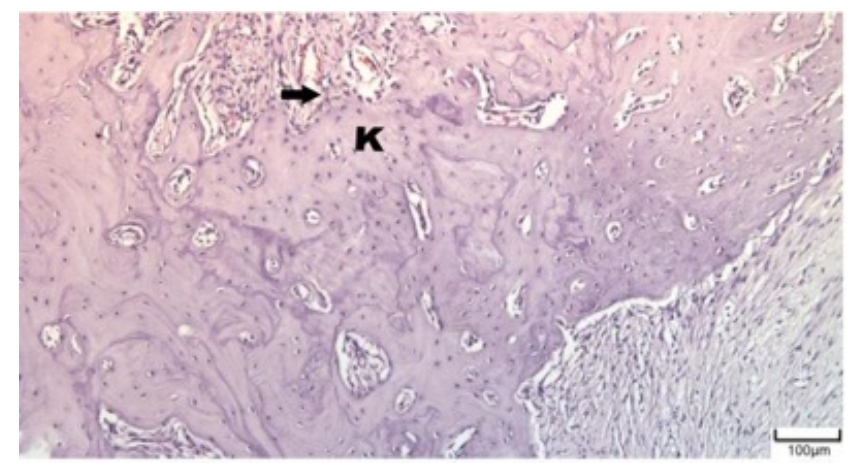

Figure 6. New bone formation of extraction socket (arrow, K) in maxilla, group B (HE X200).

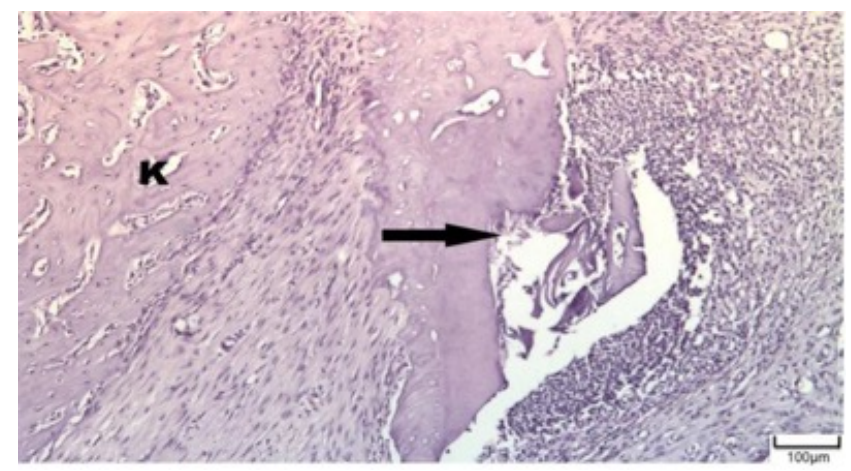

Figure 7. Neutrophil polymorphs (arrow) and new bone formation (K) of extraction socket in mandible group B (HE X100).

The distribution of new bone formation and sequester according to the inflammation in the maxilla and mandibles of all groups is shown in Table 5. No statistically significant difference was found between new bone formation levels of the groups about the bone inflammation in both jaw extraction sockets $(\mathrm{P}>0.05)$. Sequester presence was found to be higher in specimens with severe inflammation, but no statistically significant difference was found in both jaws $(\mathrm{P}>0.05)$.

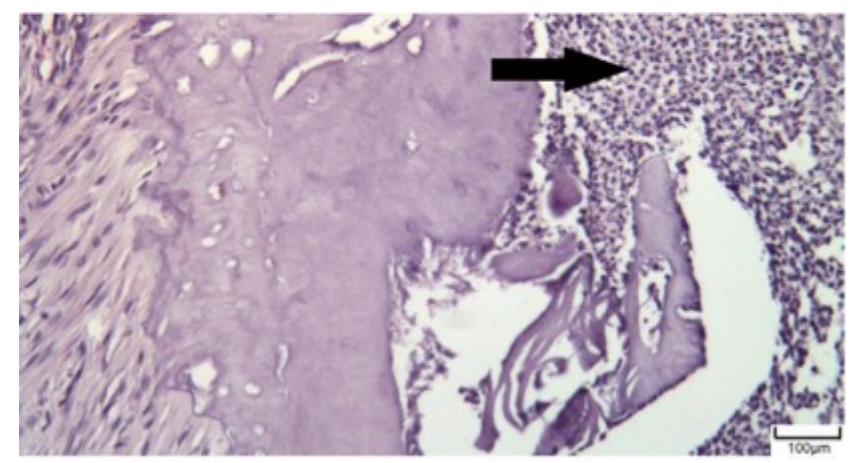

Figure 8. Neutrophil polymorphs (arrow) with sequester of extraction socket in mandible, group B (HE X200).

\section{Discussion}

Although there are many studies investigating osteoporosis in the jaw that occurred due to a bisphosphonate, the reason for the inability to explain the role of bisphosphonates in the pathophysiology of the osteonecrosis is defined as a lack of an established animal model [26]. The primary aim of an animal model is to simulate the clinical conditions of osteonecrosis of the jaw due to bisphosphonates [27]. It has been reported that the ideal animal model involves osteonecrosis developing in the oral cavity in conjunction with bisphosphonate treatment without radiotherapy [26]. It is thought that there are common co-factors relevant to the development of BRONJ in humans in addition to bisphosphonate treatment. Those factors include dental trauma, periodontal disease, and immune insufficiency. Moreover, it is also necessary to couple those co-factors with bisphosphonate stimulating osteonecrosis observed in humans. BRONJ is known to vary in the animal model. In our study, considering that the groups were assigned four weeks after the ovariectomy, one dose of subcutaneous $7.5 \mu \mathrm{g} / \mathrm{kg} \mathrm{ZOL}$ was administered weekly to the control group, two weeks for group A, and three weeks for group B. The aim was to observe changes caused by ZOL on the bone by prolonging the duration of a regular dose.

Because of a higher turnover rate and remodelling in the posterior mandible about the anterior mandible, BRONJ development and inflammation is often observed in the posterior mandible [28,29]. In our study, while severe inflammation was observed in all rats $(100 \%)$ in group B, inflammation with the same severity was observed in 10 rats (71.4\%) in the control group and eight rats (57.1\%) in group A $(\mathrm{P}=0.025)$. The severity of inflammation in group $\mathrm{B}$ was significantly higher than in group $\mathrm{A}(\mathrm{P}=0.016 ; \mathrm{P}<0.05)$. A statistically significant difference was observed in the new bone formation levels of the rats in all groups in the tooth extraction region $(\mathrm{P}<0.01)$. The new bone formation level of group A was found to be significantly higher $(\mathrm{P}<0.05 ; \mathrm{P}<0.01)$ than in the control group and group $\mathrm{B}(\mathrm{P}=0.001$ and $\mathrm{P}=0.018$, respectively). The presence of sequester in group $\mathrm{B}(\mathrm{P}<0.05)$ was found to be significantly higher than in the control group and group $\mathrm{A}(\mathrm{P}=0.013$ and $\mathrm{P}=0.046$, respectively). The distribution of severe inflammation in the maxilla and mandibles in all groups was in all $7(100 \%)$ mandibles of the control group and group B, while it was observed equally in both jaws in 4 rats $(57 \%)$ in group B. The advanced new bone formation in the maxilla and mandibles of the control group were observed in all specimens: $7(100 \%)$ and $5(71 \%)$ in group A and $3(43 \%)$ and $2(29 \%)$ in group B. The distribution of the presence of sequesters in the maxilla and mandible of all groups was $1(14 \%)$ mandible in control, $1(14 \%)$ maxilla and $1(14 \%)$ mandible in group A, and $3(43 \%)$ maxilla and 5 $(71 \%)$ mandibles in group B. No statistically significant difference was found in new bone formation levels and sequesters presence between the groups about the bone inflammation in the maxillary and mandibular extraction sockets $(\mathrm{P}>0.05)$. In our study, consistent with the literature, we believe that the reason for severe inflammation in the 
mandible is poor nutrition and late resultant recovery due to its cortical structure.

In the study conducted by Sonis et al. BRONJ development was simulated in rats by administration of ZOL and DX before tooth extraction, the authors reported that they employed the same treatment method with oncology patients undergoing bisphosphonate therapy. It was reported that mucosa in the extraction region was intact on $\mathrm{d} 14$ in the control group, and large or focal ulceration was observed in many rats. Among animals treated with ZOL and DX, mucosal ulcerations were observed on d 28 in $80 \%$ of rats with a maxillary molar tooth extracted and $33.3 \%$ of rats with a mandibular molar tooth extracted. Moreover, in rats that were administered ZOL and DX twice, ulceration was observed in the maxilla in $50 \%$ and the mandible in $60 \%$, whereas ulceration was observed in the maxilla in $80 \%$ and the mandible in $60 \%$ of rats that were administered ZOL and DX 3 times. While sequester was found in all rats with mucosal ulceration, it was not observed in rats with intact mucosa [19]. In our study, the intraoral mucosa of all 42 rats was intact, and a statistically significant difference was found between groups regarding sequester rate $(\mathrm{P}<0.01)$. The rate of sequester presence in the rats of group $\mathrm{B}$ that were administered 1 dose of subcutaneous $7.5 \mu \mathrm{g} / \mathrm{kg}$ ZOL per week and $1 \mathrm{mg} / \mathrm{kg}$ DX daily for $3 \mathrm{w}$ was found to be significantly higher $(\mathrm{P}<0.05)$ than that of the group $\mathrm{A}$ rats that were administered the same dose for $2 \mathrm{w}(\mathrm{P}=0.046)$, as well as the control group $(\mathrm{P}=0.013)$. No statistically significant difference was found between the control group and group A regarding sequester presence $(\mathrm{P}>0.05)$. However, a statistically significant difference was observed in the presence of sequester in rats with mandibular extraction sockets from all groups $(\mathrm{P}<0.05)$. We believe that the reason for the higher sequester rate in group $\mathrm{B}$ compared to the other study groups was caused by the higher doses of ZOL and DX received than the other groups.

Growth and differentiation factors have been recently produced at desired amounts using recombinant technology, but production costs are high. Therefore, it is recommended to obtain optimal effects using the factor at a minimal dose. The desired amount of bone should be formed using minimal doses to obtain the optimal effect in the ectopic application of BMP-2. It is known that BMP is also effective in solution form, but an adequate bone induction can be ensured using less BMP when it is used with the carrier. Different carrying materials are used for BMP. However, a collagen carrier is often used due to ease of access to the studies, the ability of resorption, and a lack of cytotoxicity. In the treatment of osteonecrosis found in patients receiving bisphosphonate, the efficiency of mechanisms facilitating bone recovery and preventing the development of complications is not known. This is the first study to evaluate the efficiency of BMPs on BRONJ.

It is reported that among BMPs, BMP-2 has the highest osteoinductive effect, and the amount of bone formed in the implantation site is directly proportional to the dose of protein applied [30]. Studies have suggested that BMP-2 has effects on mandibular bone recovery and that the ideal dose of BMP-2 for new bone formation ranges between $1 \mu \mathrm{g}$ and ten $\mu \mathrm{g}$ [31]. In our study, a statistically significant difference was found between groups with mandibular tooth extraction regarding new bone formation levels $(\mathrm{P}<0.05)$. While the advanced level of new bone formation was observed in $12(85.7 \%)$ rats in group A and $5(35.7 \%)$ in group B, the new bone formation level of group B was found to be significantly higher than the control group. The new bone formation level of group A was found to be significantly higher than in the control group, and group B.

Inflammation was observed in the extraction sockets following ZOL and DX administration, but also new bone formation was observed from administering rh-BMP-2 for increasing wound healing. A $2 \mu \mathrm{g}$ dose of rhBMP-2 was sufficient for new bone formation in group A but was not adequate for group B (with higher ZOL doses administered). An increased rhBMP-2 dosage on bone healing after ZOL treatment in ovariectomized rats could lead to new bone formation.

Table 1. Flow chart of the study.

\begin{tabular}{llll}
\hline & Control group (14 rats) & Group A (14 rats) \\
\hline Zoledronic acid injections & Once a week for $2 \mathrm{w}$ & Once a week for $2 \mathrm{w}$ \\
\hline Dexamethasone injections & Every day for $15 \mathrm{~d}$ & Every day for $15 \mathrm{~d}$ & Once a week for $3 \mathrm{w}$ \\
\hline Extractions $\left(15^{\text {th }} \mathrm{d}\right)$ & + & + & - \\
\hline Extractions $\left(21^{\text {st }} \mathrm{d}\right)$ & - & 7 rats \\
\hline Right maxillary molar tooth extraction & 7 rats & 7 rats & 7 rats \\
\hline Right mandibular molar tooth extraction & 7 rats & 7 rats & Immediately after extraction \\
\hline RhBMP-2 placement & - & Immediately after extraction
\end{tabular}


Table 2. The distribution of weights of rats in all groups before procedures.

\begin{tabular}{|c|c|c|c|}
\hline Weights of rats before procedures $(\mathrm{g})$ & Control (14 rats) Avg \pm SD & Group A (14 rats) Avg \pm SD & Group B (14 rats) Avg \pm SD \\
\hline Ovariectomy & $222.58 \pm 13.86$ & $215.30 \pm 21.10$ & $184.01 \pm 17.99$ \\
\hline First injection & $273.76 \pm 12.40$ & $267.23 \pm 24.21$ & $236.19 \pm 18.72$ \\
\hline Tooth Extraction & $233.25 \pm 30.23$ & $235.11 \pm 24.78$ & $174.86 \pm 19.69$ \\
\hline Sacrification & $286.22 \pm 24.35$ & $274.43 \pm 28.97$ & $223.04 \pm 27.43$ \\
\hline$+p$ & $0.001^{* *}$ & $0.001^{* *}$ & $0.001^{* *}$ \\
\hline \multirow[t]{2}{*}{${ }^{++}$Post-hoc evaluation } & $1<2.4^{\star *}$ & $1<2.3 .4^{* *}$ & $1<2.4^{* *}$ \\
\hline & $3<2.4^{* *}$ & $3<2.4^{* *}$ & $3<1.2 .4^{* *}$ \\
\hline
\end{tabular}

+Variance analyse; ${ }^{++}$post-hoc Bonferroni test, ${ }^{* *} p<0.01$

Table 3. The average weight differences of rats in all groups before procedures.

\begin{tabular}{|c|c|c|c|c|}
\hline & $\begin{array}{l}\text { Control (14 rats) Avg } \pm \\
\text { SD }\end{array}$ & $\begin{array}{l}\text { Group A (14 rats) Avg } \\
\pm \text { SD }\end{array}$ & $\begin{array}{l}\text { Group B (14 rats) Avg } \\
\pm \text { SD }\end{array}$ & $\mathbf{p}$ \\
\hline Between ovariectomy and first injection period & $51.18 \pm 9.08$ & $51.93 \pm 12.81$ & $52.18 \pm 10.93$ & 0.970 \\
\hline Between first injection and tooth extraction period & $40.51 \pm 25.03$ & $32.12 \pm 12.63$ & $61.33 \pm 5.41$ & $0.001^{\star \star}$ \\
\hline Between tooth extraction and sacrification period & $52.97 \pm 22.95$ & $39.32 \pm 17.50$ & $48.18 \pm 14.01$ & 0.155 \\
\hline Between ovariectomy and sacrification period & $63.64 \pm 28.97$ & $59.12 \pm 19.07$ & $39.03 \pm 14.69$ & $0.011^{*}$ \\
\hline
\end{tabular}

One-way ANOVA; ${ }^{*} p<0.05 ;{ }^{* *} p<0.01$

Table 4. The distribution of histologic findings in all specimens from each group.

\begin{tabular}{|c|c|c|c|c|}
\hline & Control n (\%) & Group A n (\%) & Group B n (\%) & $\mathbf{P}$ \\
\hline \multicolumn{5}{|c|}{ Inflammation } \\
\hline+ & $4(28.6 \%)$ & $6(42.9 \%)$ & $0(0 \%)$ & $0.025^{*}$ \\
\hline++ & $10(71.4 \%)$ & $8(57.1 \%)$ & $14(100 \%)$ & \\
\hline $\begin{array}{l}\text { New } \\
\text { formation }\end{array}$ & & & & \\
\hline++ & $14(100 \%)$ & $2(14.3 \%)$ & $9(64.3 \%)$ & $0.001^{* *}$ \\
\hline+++ & $0(0 \%)$ & $12(85.7 \%)$ & $5(35.7 \%)$ & \\
\hline \multicolumn{5}{|l|}{ Sequester } \\
\hline Present & $1(7.1 \%)$ & $2(14.3 \%)$ & $8(57.1 \%)$ & $0.005^{* *}$ \\
\hline Absent & $13(92.9 \%)$ & $12(85.7 \%)$ & $6(42.9 \%)$ & \\
\hline
\end{tabular}

Chi-square test; ${ }^{*} \mathrm{P}<0.05 ;{ }^{* *} \mathrm{P}<0.01$

Table 5. The distribution of new bone formation and sequester according to the inflammation in maxilla and mandible of all groups.

\begin{tabular}{|c|c|c|c|}
\hline \multirow[t]{3}{*}{ Maxilla } & \multicolumn{2}{|c|}{ Inflammation } & \multirow[t]{3}{*}{$\mathbf{P}$} \\
\hline & + & ++ & \\
\hline & n (\%) & n (\%) & \\
\hline \multicolumn{3}{|c|}{ New bone formation } & \multirow[b]{2}{*}{1.000} \\
\hline++ & $4(57.1 \%)$ & $7(50.0 \%)$ & \\
\hline
\end{tabular}

\begin{tabular}{|c|c|c|c|}
\hline+++ & $3(42.9 \%)$ & $7(50.0 \%)$ & \\
\hline \multicolumn{4}{|c|}{ Sequester } \\
\hline Present & $0(0 \%)$ & $4(28.6 \%)$ & 0.255 \\
\hline Absent & $7(100 \%)$ & $10(71.4 \%)$ & \\
\hline \multicolumn{4}{|l|}{ Mandible } \\
\hline \multicolumn{4}{|c|}{ New bone formation } \\
\hline++ & $1(33.3 \%)$ & $13(72.2 \%)$ & 0.247 \\
\hline+++ & $2(66.7 \%)$ & $5(27.8 \%)$ & \\
\hline \multicolumn{4}{|c|}{ Sequester } \\
\hline Present & $0(0 \%)$ & $7(38.9 \%)$ & 0.521 \\
\hline Absent & $3(100 \%)$ & $11(61.1 \%)$ & \\
\hline
\end{tabular}

Fisher's exact chi-square test

\section{Ethical Consideration}

The research approved by Yeditepe University Institutional Animal Care and Use Committee. Approval number 19012009 (http://yudetam.yeditepe.edu.tr/etik.php).

\section{References}

1. Green JR. Bisphosphonates: preclinical review. Oncologist 2004; 9 Suppl 4: 3-13.

2. Santini D, Vespasiani Gentilucci U, Vincenzi B, Picardi A, Vasaturo F, La Cesa A, Onori N, Scarpa S, Tonini G. The antineoplastic role of bisphosphonates: from basic 
research to clinical evidence. Ann Oncol 2003; 14: 1468-1476.

3. Khan AA, Sandor GK, Dore E, Morrison AD, Alsahli M, Amin F. Canadian Taskforce on Osteonecrosis of the Jaw. Bisphosphonate-associated osteonecrosis of the jaw. J Rheumatol 2009; 36: 478-490.

4. Migliorati CA, Siegel MA, Elting LS. Biphosphonateassociated osteonecrosis: a long-term complication of bisphosphonate treatment. Lancet Oncol 2006; 7: 508-514.

5. Bilezikian JP. Osteonecrosis of the jaw-do bisphosphonates pose a risk? N Engl J Med 2006; 355: 2278-2281.

6. Black DM, Delmas PD, Eaastell R, Reid IR, Boonen S, Cauley JA. HORIZON Pivotal Fracture Trial. Once-yearly zoledronic acid for treatment of postmenopausal osteoporosis. N Engl J Med 2007; 356: 1809-1822.

7. Sahin S. A nephrologists view to renal safety of bisphosphonates. J Breast Health 2007; 3: 120-124.

8. Diel IJ, Bergner R, Grotz KA. Adverse effects of bisphosphonates: current issues. J Support Oncol 2007; 5: 475-548.

9. Green JR. Chemical and biological prerequisites for novel bisphosphonate molecules: Results of comparative preclinical studies. Semin Oncol 2001; 28: 4-10.

10. Li EC, Davis LE. Zoledronic acid: a new parenteral bisphosphonate. Clin Ther 2003; 25: 2669-2708.

11. Benford HL, McGowan NW, Helfrich MH, Nuttall ME, Rogers MJ. Visualization of bisphosphonate-induced caspase-3 activity in apoptotic osteoclasts in vitro. Bone 2001; 28: 465-473.

12. Dunford JE, Thompson K, Coxon FP, Luckman SP, Hahn FM, Poulter CD, Ebetino FH, Rogers MJ. Structureactivity relationships for inhibition of farnesyl diphosphate synthase in vitro and inhibition of bone resorption in vivo by nitrogen-containing bisphosphonates. J Pharmacol Exp Ther 2001; 296: 235-242.

13. Komatsubara S, Mori S, Mashiba T, Li J, Nonaka K, Kaji Y. Suppressed bone turnover by long-term bisphosphonate treatment accumulates microdamage but maintains intrinsic material properties in cortical bone of dog rib. J Bone Miner Res 2004; 19: 999-1005.

14. Allen MR, Burr DB. Bisphosphonate effects on bone turnover, microdamage, and mechanical properties: what we think we know and what we know that we dont know. Bone 2011; 49: 56-65.

15. Marx RE, Sawatari Y, Fortin M, Broumand V. Bisphosphonate- induced exposed bone (osteonecrosis/ osteopetrosis) of the jaws: risk factors, recognition, prevention, and treatment. J Oral Maxillofac Surg 2005; 63: 1567-1575.

16. Ruggiero SL, Mehrotra B, Rosenberg TJ, Engroff SL. Osteonecrosis of the jaws associated with the use of bisphosphonates: a review of 63 cases. J Oral Maxillofac Surg 2004; 62: 527-534.
17. Bagan JV, Murillo J, Jimenez Y, Poveda R, Milian MA, Sanchis JM, Silvestre FJ, Scully C. Avascular jaw osteonecrosis in association with cancer chemotherapy: series of 10 cases. J Oral Pathol Med 2005; 34: 120-123.

18. Egermann M, Goldhahn J, Schneider E. Animal models for fracture treatment in osteoporosis. Osteoporos Int 2005; 16: 129-138.

19. Sonis ST, Watkins BA, Lyng GD, Lerman M, Anderson KC. Bony changes in the jaws of rats treated with zoledronic acid and dexamethasone before dental extractions mimic bisphosphonates-related osteonecrosis in cancer patients. Oral Oncol 2009; 2: 164-172.

20. Wronski TJ, Yen CF, Qi H, Dann LM. Parathyroid hormone is more effective than estrogen or bisphosphonates for restoration of lost bone mass in ovariectomized rats. Endocrinology 1993; 132: 823-831.

21. Søgaard CH, Wronski TJ, McOsker JE, Mosekilde L. The positive effect of parathyroid hormone on femoral neck bone strength in ovariectomized rats is more pronounced than that of estrogen or bisphosphonates. Endocrinology 1994; 134: 650-657.

22. Arisawa EA, Brandão AA, Almeida JD, da Rocha RF. Calcitonin in the bone- guided regeneration of mandibles in ovariectomized rats: densitometric, histologic and histomorphometric analysis. Int J Oral Maxillofac Surg 2008; 37: 47-53.

23. Urist MR, Mikulski A, Lietze A. Solubilized and insolubilized bone morphogenetic protein. Proc Natl Acad Sci USA 1979; 76: 1828-1832.

24. Groeneveld EH, Burger EH. Bone morphogenetic proteins in human bone regeneration. Eur J Endocrinol 2000; 142: 9-21.

25. Boyne PJ. Animal studies of application of rhBMP-2 in maxillofacial reconstruction. Bone 1996; 19: 83S-92S.

26. Khosla S, Burr D, Cauley J, Dempster DW, Ebeling PR, Felsenberg D. Bisphosphonate-associated osteonecrosis of the jaw: report of a task force of the American Society for Bone and Mineral Research. J Bone Miner Res 2007; 22: 1479-1491.

27. Allen MR. Animal models of osteonecrosis of the jaw. J Musculoskelet Neuronal Interact 2007; 7: 358-360.

28. Boonyapakorn T, Schirmer I, Reichart PA, Sturm I, Massenkeil G. Bisphosphonate-induced osteonecrosis of the jaws: a prospective study of 80 patients with multiple myeloma and other malignancies. Oral Oncol 2008; 44: 857-869.

29. Badros A, Weikel D, Salama A, Goloubeva O, Schneider A, Rapoport A, Fenton R, Gahres N, Sausville E, Ord R, Meiller T. Osteonecrosis of the jaw in multiple myeloma patients: clinical features and risk factors. J Clin Oncol 2006; 24: 945-952.

30. Wang EA, Rosen V, DAlessandro JS, Bauduy M, Cordes P, Harada T, Israel DI, Hewick RM, Kerns KM, LaPan P. Recombinant human bone morphogenetic protein induces bone formation. Proc Natl Acad Sci U S A 1990; 87: 2220-2224. 
31. Arosarena OA, Collins WL. Bone regeneration in the rat mandible with bone morphogenetic protein-2: a comparison of two carriers. Otolaryngol Head Neck Surg 2005; 132: 592-597.

\section{${ }^{*}$ Correspondence to}

Berkem Atalay

Department of Oral Surgery

Istanbul University

Istanbul

Turkey 